\title{
Aqueous Extract of Kalmegh (Andrographis paniculata) Leaves as Green Inhibitor for Mild Steel in Hydrochloric Acid Solution
}

\author{
Ambrish Singh, ${ }^{1}$ V. K. Singh, ${ }^{1}$ and M. A. Quraishi ${ }^{2}$ \\ ${ }^{1}$ Department of Chemistry, Udai Pratap Autonomous College, Varanasi 221002, India \\ ${ }^{2}$ Department of Applied Chemistry, Institute of Technology, Banaras Hindu University, Varanasi 221005, India
}

Correspondence should be addressed to M. A. Quraishi, maquraishi.apc@itbhu.ac.in

Received 10 May 2010; Revised 15 June 2010; Accepted 23 June 2010

Academic Editor: Ravin Kumar Dayal

Copyright (C 2010 Ambrish Singh et al. This is an open access article distributed under the Creative Commons Attribution License, which permits unrestricted use, distribution, and reproduction in any medium, provided the original work is properly cited.

\begin{abstract}
The inhibition of the corrosion of mild steel in hydrochloric acid solution by the extract of Kalmegh (Andrographis paniculata) leaves extract has been studied using weight loss, electrochemical impedance spectroscopy, linear polarization, and potentiodynamic polarization techniques. Inhibition was found to increase with increasing concentration of the extract. The effect of temperature, immersion time, and acid concentration on the corrosion behavior of mild steel in $1 \mathrm{M} \mathrm{HCl}$ with addition of extract was also studied. The inhibition was assumed to occur via adsorption of the inhibitor molecules on the metal surface. The adsorption of the molecules of the extract on the mild steel surface obeyed the Langmuir adsorption isotherm. The protective film formed on the metal surface was analyzed by FTIR spectroscopy. The results obtained showed that the extract of Kalmegh (Andrographis paniculata) leaves extract could serve as an effective inhibitor of the corrosion of mild steel in hydrochloric acid media.
\end{abstract}

\section{Introduction}

Acid solutions are commonly used for removal of undesirable scale and rust in metal finishing industries, cleaning of boilers, and heat exchangers. Among these, hydrochloric acid is one of the most widely used agents in the process of acid pickling. Use of inhibitors is one of the most practical methods for protection against corrosion especially in acid solutions to prevent unexpected metal dissolution and acid consumption [1]. A mild steel corrosion phenomenon has become important particularly in acidic media because of the increased industrial applications of acid solutions [2]. The known hazardous effect of most synthetic corrosion inhibitors is the motivation for the use of some natural products. The use of chemical inhibitors has been limited because of the environmental threat, recently, due to environmental regulations. Plant extracts have become important because they are environmentally acceptable, inexpensive, readily available and renewable sources of materials, and ecologically acceptable [3]. Plant products are organic in nature and some of the constituents including tannins, organic and amino acids, alkaloids, and pigments are known to exhibit inhibiting action. Moreover, they can be extracted by simple procedures with low cost $[4,5]$.

Leaves extracts are used as common corrosion inhibitors. The anticorrosion activity of Meethi neem (Murraya koenigii), Amla (Emblica officianilis), Black Myrobalan (Terminalia chebula), soapberry (Sapindus trifolianus), and Shikakai (Accacia conicianna) was investigated. Corrosion inhibition has also been studied for the extracts of Beautiful swertia (Swertia angustifolia). Similar results were also shown by Eucalyptus (Eucalyptus sp.) leaves, Jambolan (Eugenia jambolana), sugar-apple (Annona squamosa), Babul (Acacia Arabica), Papaya (Carica papaya), Neem (Azadirachta indica) and Ironweed (Vernonia amydalina) were used for steel in acid media. Attap palm (Nypa fructicans) wurmb leaves were studied for the corrosion inhibition of mild steel in $\mathrm{HCl}$ media. Castor (Ricimus communis) leaves were studied for the corrosion inhibition of mild steel in acid media in addition to the use of herbs such as coriander, hibiscus, anis, black cumin, and garden cress as new type of green inhibitors for acidic corrosion of steel [6-11].

Seeds are of great concern for corrosion inhibition studies. Tobacco (Nicotiana), black pepper (Piper nigrum), 
castor seeds oil (Ricinus communis), acacia gum, and lignin can be good inhibitors for steel in acid medium. Papaya, Poinciana pulcherrima, Fedegoso (Cassia occidentalis), and Datura (Datura stramonmium) seeds are efficient corrosion inhibitors for steel [12-14].

The anticorrosion activity of onion, garlic, and bitter gourd for mild steel in $\mathrm{HCl}$ media showed good results studied. Oil extracts of Ginger, jojoba, eugenol, acetyleugenol, artemisia oil, and Pennyroyal (Mentha pulegium) are used for corrosion inhibition of steel in acid media. Berberine an alkaloid isolated from Captis was studied for its anticorrosion effect for mild steel corrosion in $\mathrm{H}_{2} \mathrm{SO}_{4}$ medium.

Saps of certain plants are very useful corrosion inhibitors. Apple of Sodom (Calotropis procera), Azydracta indica, and Auforpio turkiale sap are useful as acid corrosion inhibitors. The extract of Datura was used as corrosion inhibitor for mild steel in acid medium. Quinine has been studied for its anticorrosive effect of carbon steel in $1 \mathrm{M} \mathrm{HCl}$. The inhibitive effect of Mosquito plant (Occmium viridis) extract on the acid corrosion of mild steel was studied. The inhibition effect of Winged prickly ash (Zenthoxylum alatum) extract on the corrosion of mild steel in aqueous Orthophosphonic acid was investigated [15-18].

As a contribution to the current interest on environmentally friendly, green, corrosion inhibitors, the present study investigates the inhibiting effect of leaves extract of Kalmegh (Andrographis paniculata), a green inhibitor which is the Kalmegh of the Ayurveda, which is an erect annual herb extremely bitter in taste in each and every part of the plant body. The plant is known in north-eastern India as "Mahatita", literally "king of bitters" due to its bitter taste. Kinetic and activation parameters that govern metal corrosion have been evaluated.

\section{Experimental}

2.1. Preparation of Kalmegh (Andrographis Paniculata) Leaves Extract. Kalmegh (Andrographis paniculata) leaves were dried and ground to powder form. Dried ( $5 \mathrm{~g}$ ) powder was soaked in double distilled water $(500 \mathrm{~mL})$ and refluxed for $5 \mathrm{~h}$. The aqueous solution was filtered and concentrated to $100 \mathrm{~mL}$. This extract was used to study the corrosion inhibition properties. Corrosion tests were performed on a mild steel of the following percentage composition: Fe 99.30\%, C 0.076\%, Si 0.026\%, Mn 0.192\%, P 0.012\%, Cr $0.050 \%$, Ni $0.050 \%, \mathrm{Al} 0.023 \%$, and $\mathrm{Cu} 0.135 \%$, which were polished successively with fine grade emery papers from 600 to 1200 grade. The specimens were washed thoroughly with double distilled water and finally degreased with acetone and dried at room temperature. The aggressive solution $1 \mathrm{M} \mathrm{HCl}$ was prepared by dilution of analytical grade $\mathrm{HCl}(37 \%)$ with double distilled water and all experiments were carried out in unstirred solutions.

2.2. Weight Loss Method. Weight loss measurements were performed on the mild steel samples with a rectangular form of size $2.5 \mathrm{~cm} \times 2.0 \mathrm{~cm} \times 0.025 \mathrm{~cm}$ in one molar $\mathrm{HCl}$ solution with and without addition of different concentrations of seed's extract. Every sample was weighed by an electronic balance and then placed in the acid solution $(100 \mathrm{~mL})$. The duration of the immersion was $3 \mathrm{~h}$ at the temperature range from 308 to $338 \mathrm{~K}$. After immersion, the surface of the specimen was cleaned by double distilled water followed by rinsing with acetone and the sample was weighed again in order to calculate inhibition efficiency $(E \%)$ and the corrosion rate $\left(C_{R}\right)$. For each experiment, a freshly prepared solution was used and the solution temperature was thermostatically controlled at a desired value.

The aggressive solution $(1 \mathrm{M} \mathrm{HCl})$ was prepared by dilution of an analytical grade $\mathrm{HCl}$ with double distilled water. The surface coverage $(\theta)$ and inhibition efficiency $(E \%)$ were determined by using the following equations

The surface coverage $(\theta)$ and inhibition efficiency $(E \%)$ was determined by using following equation

$$
\begin{gathered}
\theta=\frac{w_{0}-w_{i}}{w_{0}}, \\
E \%=\frac{w_{0}-w_{i}}{w_{0}} \times 100,
\end{gathered}
$$

where $w_{i}$ and $w_{0}$ are the weight loss values in presence and absence of inhibitor, respectively.

The corrosion rate $\left(C_{R}\right)$ of mild steel was calculated using the following relation:

$$
C_{R}(\mathrm{~mm} / \mathrm{y})=\frac{87.6 \times w}{a t D},
$$

where $w$ is corrosion weight loss of mild steel $(\mathrm{mg}), a$ the area of the coupon $\left(\mathrm{cm}^{2}\right), t$ is the exposure time $(\mathrm{h})$, and $D$ is the density of mild steel $\left(\mathrm{g} \mathrm{cm}^{-3}\right)$.

2.3. Electrochemical Measurements. The electrochemical studies were made using a three-electrode cell assembly at room temperature. The mild steel of $1 \mathrm{~cm}^{2}$ was the working electrode, platinum electrode was used as an auxiliary electrode, and standard calomel electrode (SCE) was used as reference electrode. The working electrode was polished with different grades of emery papers, washed with water, and degreased with acetone. All electrochemical measurements were carried out using GamryPotentiostat/Galvanostat (Model G-300) with EIS software Gamry Instruments Inc., USA. Gamry applications include software DC 105 for corrosion and EIS 300 for EIS measurements and Echem Analyst version 5.50 software packages for data fitting. Prior to the electrochemical measurement, a stabilization period of 30 minutes was allowed, which was proved to be sufficient to attain a stable value of $E_{\text {corr }}$.

The linear polarization study was carried out from cathodic potential of $-20 \mathrm{mV}$ versus $E_{\text {corr }}$ to an anodic potential of $+20 \mathrm{mV}$ versus $E_{\text {corr }}$ with a scan rate $0.125 \mathrm{mV} \mathrm{s}^{-1}$ to determine the polarization resistance $\left(R_{p}\right)$. From the measured polarization resistance value, the inhibition efficiency has been calculated using the following relationship:

$$
E \%=\frac{R_{p}^{i}-R_{p}^{0}}{R_{p}^{\prime}} \times 100
$$


where $R_{p}^{0}$ and $R_{p}^{\prime}$ are the polarization resistance in absence and in presence of inhibitor, respectively. Tafel curves were obtained by changing the electrode potential automatically from -250 to $+250 \mathrm{mV}$ versus corrosion potential $\left(E_{\text {corr }}\right)$ at a scan rate of $1 \mathrm{mV} \mathrm{s}^{-1}$. EIS measurements were carried out in a frequency range from $100 \mathrm{kHz}$ to $0.00001 \mathrm{kHz}$ with amplitude of $10 \mathrm{mV}$ peak-to-peak using AC signal at $E_{\text {corr }}$. All experiments were measured after immersion for $30 \mathrm{~min}$ in $1 \mathrm{M} \mathrm{HCl}$ with and without addition of inhibitor. The linear Tafel segments of anodic and cathodic curves were extrapolated to corrosion potential to obtain corrosion current densities $\left(I_{\text {corr }}\right)$. The inhibition efficiency was evaluated from the measured $I_{\text {corr }}$ values using the following relationship:

$$
E \%=\frac{I_{\text {corr }}^{0}-I_{\text {corr }}^{i}}{I_{\text {corr }}^{0}} \times 100,
$$

where $I_{\text {corr }}^{0}$ and $I_{\text {corr }}^{i}$ are the corrosion current in absence and in presence of inhibitor, respectively. The charge transfer resistance values were obtained from the diameter of the semicircles of the Nyquist plots. The inhibition efficiency of the inhibitor has been found out from the charge transfer resistance values using the following equation:

$$
E \%=\frac{R_{\mathrm{ct}}^{i}-R_{\mathrm{ct}}^{0}}{R_{\mathrm{ct}}^{\prime}} \times 100,
$$

where $R_{\mathrm{ct}}^{0}$ and $R_{\mathrm{ct}}^{\prime}$ are the charge transfer resistance in absence and in presence of inhibitor, respectively.

All electrochemical measurements were done in unstirred and nondeaerated solutions.

2.4. Fourier Transform Infrared Spectroscopy. FTIR spectra were recorded in a Thermo Nicolet-5700 FTIR spectrophotometer (USA). The mild steel specimens of size $2.5 \mathrm{~cm} \times$ $2.0 \mathrm{~cm} \times 0.025 \mathrm{~cm}$ were prepared as described above. These specimens were removed after immersing for $3 \mathrm{~h}$ in $100 \mathrm{~mL}$ of $1 \mathrm{M} \mathrm{HCl}$ solution containing $1200 \mathrm{ppm}$ of inhibitor, and specimens were washed with water and then dried. Then the FTIR reflectance accessory was applied to study the mild steel surfaces.

\section{Results and Discussion}

\subsection{Weight Loss Studies}

3.1.1. Effect of Inhibitor Concentration. Figure 1(a) represented the effect of inhibitor concentration on inhibition efficiency in $\mathrm{HCl}$. The extract showed maximum inhibition efficiency of $98.09 \%$ in $\mathrm{HCl}$ and a t optimum concentration of $1200 \mathrm{ppm}$. Further increase in extract concentration did not cause any significant change in the performance of the extract. The values of percentage inhibition efficiency $(E \%)$ and corrosion rate $\left(C_{R}\right)$ obtained from weight loss method at different concentrations of Kalmegh (Andrographis paniculata) leaves extract at $308 \mathrm{~K}$ are summarized in Table 1.

3.1.2. Effect of Immersion Time. In order to assess the stability of inhibitive behaviour of the extract on a time scale, weight loss measurements were performed in $1 \mathrm{M} \mathrm{HCl}$ in absence and presence of the extract at $1200 \mathrm{ppm}$ concentration for 2 to $8 \mathrm{~h}$ immersion time at temperature $308 \mathrm{~K}$. Inhibition efficiencies were plotted against immersion time as seen from Figure 1(b). This figure shows that inhibition efficiency of the extract was increased with increasing immersion time from 2 to $8 \mathrm{~h}$ (give values). The increase in inhibition efficiency upto $8 \mathrm{~h}$ reflects the strong adsorption of constituents present in the extract on the mild steel surface, resulting in a more protective layer formed at mild steel/hydrochloric acid solution interface. Thus, Kalmegh (Andrographis paniculata) leaves extract effectively inhibits the mild steel corrosion in one molar hydrochloric acid solution.

3.1.3. Effect of Acid Concentration. The variation of inhibition efficiency with increase in acid concentration from $0.5 \mathrm{M}$ to $2 \mathrm{M}$ in the acid is shown in Figure 1(c). The decrease in inhibition efficiency of $\mathrm{HCl}$ is very less, that is, from 98.6\% to $64.7 \%$. This decrease in $E \%$ can be attributed to increased aggressiveness of solutions with increase in acid concentration.

3.1.4. Effect of Temperature. To evaluate the stability of adsorbed layer/film of inhibitor on mild steel surface as well as activation parameters of the corrosion process of steel in acidic media, weight loss measurements were carried out in the range of temperature $308-338 \mathrm{~K}$ in the absence and presence of extract at optimum concentration during $3 \mathrm{~h}$ immersion time. Results, thus, obtained are shown in Figure $1(d)$. It is evident from this figure that inhibition efficiency decreases with increasing temperature. This is due to increased rate of dissolution process of mild steel and partial desorption of the inhibitor from the metal surface with temperature [19].

The log of corrosion rate is a linear function of temperature (Arrhenius equation) [20-22]:

$$
\log \left(C_{R}\right)=\frac{-E_{a}}{2.303 R T}+A
$$

where $E_{a}$ is the apparent effective activation energy, $R$ is the general gas constant, and $A$ is Arrhenius pre-exponential factor. A plot of log of corrosion rate obtained by weight loss measurement versus $1 / T$ gave a straight line as shown in Figure 2(a) with a slope of $-E_{a} / 2.303 R$. The values of activation energy are listed in Table 2.

The data shows that the activation energy $\left(E_{a}\right)$ of the corrosion in mild steel in $1 \mathrm{M} \mathrm{HCl}$ solution in the presence of extract is higher than that in the free acid solution. The increase in the apparent activation energy for mild steel dissolution in inhibited solution may be interpreted as physical adsorption that occurs in the first stage [23] that the increase in activation energy can be attributed to an appreciable decrease in the adsorption of the inhibitor on the mild steel surface with increase in temperature.

An alternative formulation of Arrhenius equation is [24]

$$
C_{R}=\frac{R T}{N h} \exp \left(\frac{\Delta S^{*}}{R}\right) \exp \left(\frac{-\Delta H^{*}}{R T}\right),
$$




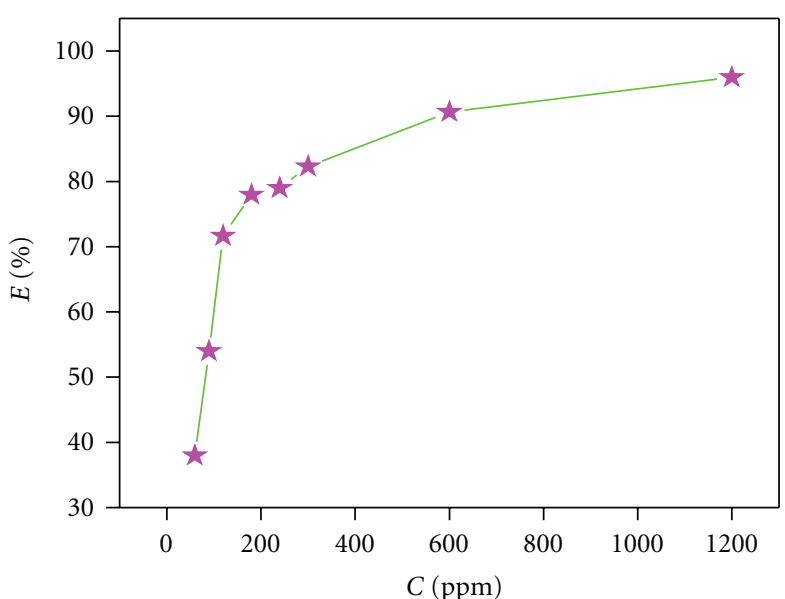

(a)

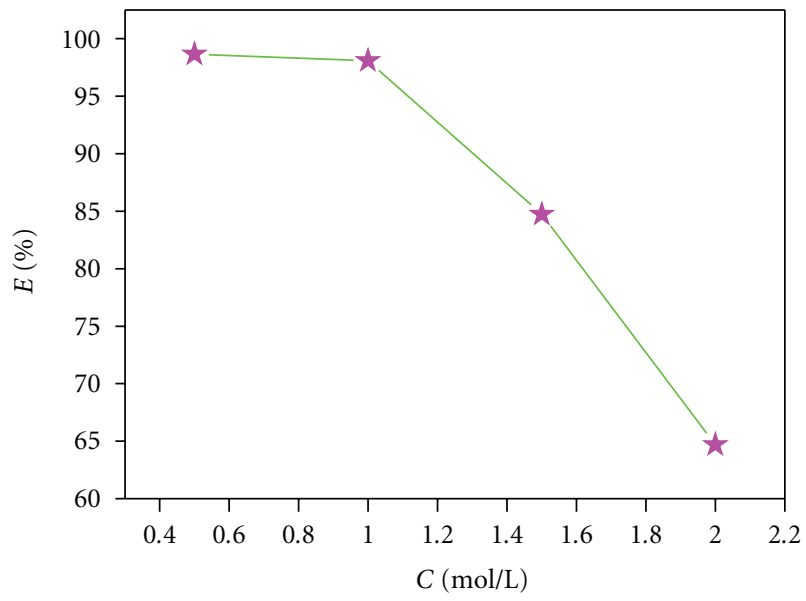

(c)

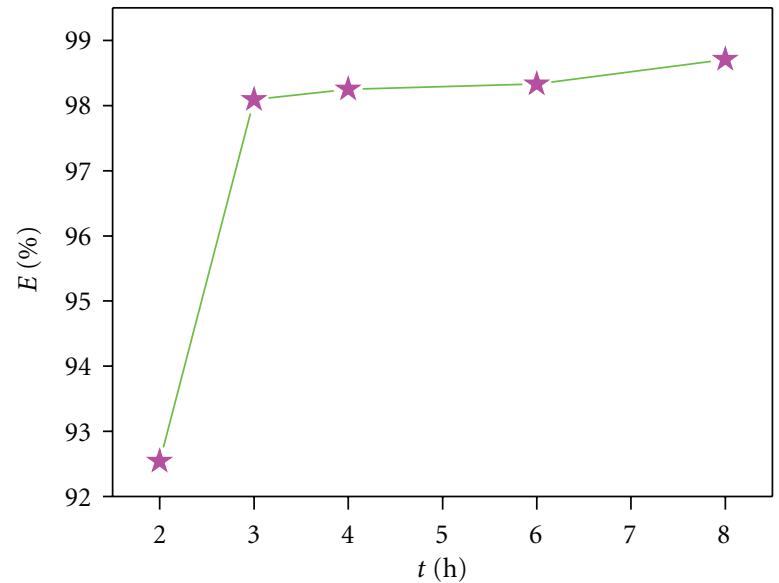

(b)

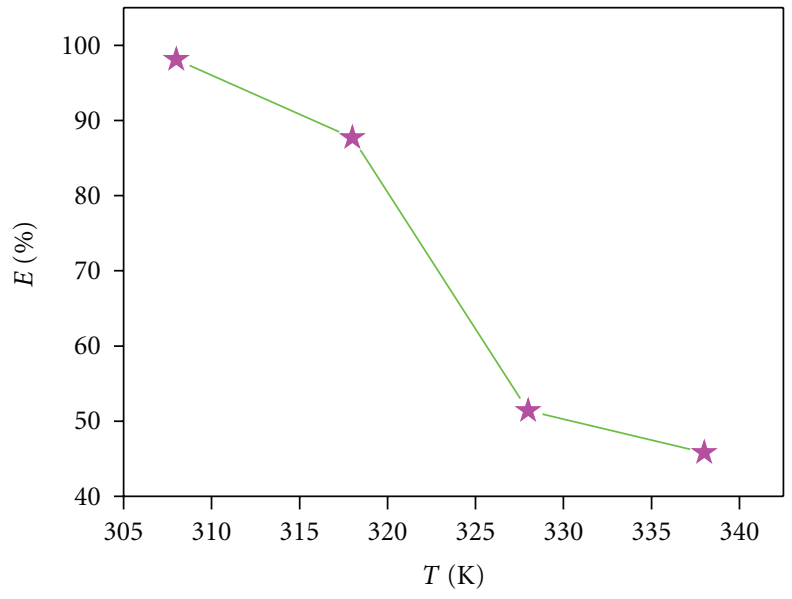

(d)

FIgURE 1: Variation of inhibition efficiency of Kalmegh (Andrographis paniculata) extracts in $1 \mathrm{M}$ HCl with (a) extract concentration, (b) immersion time, (c) acid concentration, and (d) temperature of the solution.

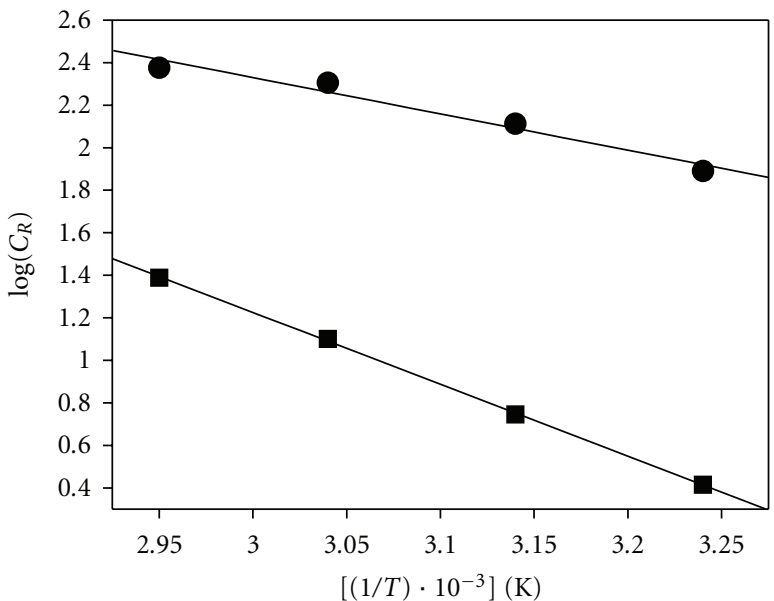

$\mathrm{Inh}+\mathrm{HCl}$

Blank $\mathrm{HCl}$

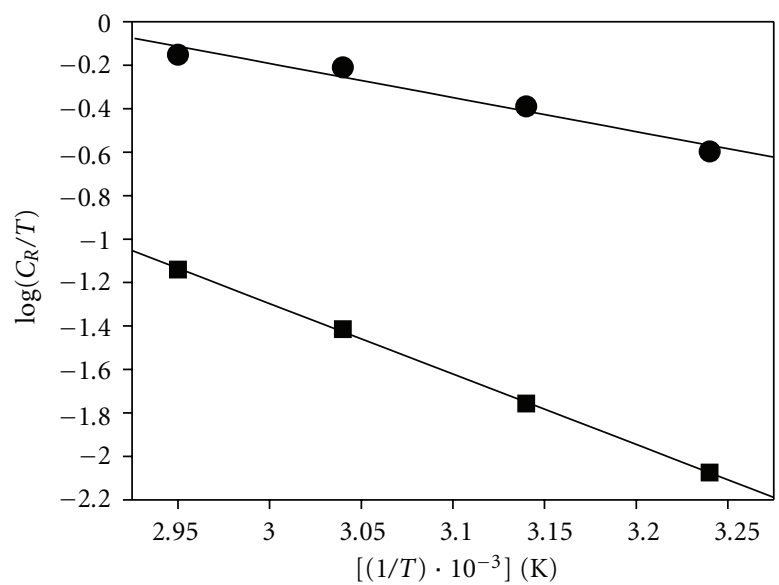

Inh $+\mathrm{HCl}$

Blank $\mathrm{HCl}$

(a)

(b)

FIgure 2: Adsorption isotherm plots for (a) $\log C_{R}$ versus $1 / T$ and (b) $\log \left(C_{R} / T\right)$ versus $1 / T$. 
TABLE 1: Corrosion parameters for mild steel in aqueous solution of $1 \mathrm{M} \mathrm{HCl}$ in presence and absence of different concentrations of Kalmegh (Andrographis paniculata) extract from weight loss measurements at $308 \mathrm{~K}$ for $3 \mathrm{~h}$.

\begin{tabular}{lccc}
\hline $\begin{array}{l}\text { Inhibitor concentration } \\
(\mathrm{ppm})\end{array}$ & $\begin{array}{c}\text { Weight loss } \\
\left(\mathrm{mg} \mathrm{cm}^{-2}\right)\end{array}$ & $E(\%)$ & $C_{R}(\mathrm{~mm} / \mathrm{y})$ \\
\hline $1 \mathrm{M} \mathrm{HCl}$ & 20.9 & - & 77.9 \\
60 & 16.3 & 63.3 & 60.5 \\
90 & 7.7 & 65.2 & 28.6 \\
120 & 7.3 & 86.7 & 27.1 \\
180 & 2.8 & 87.6 & 10.4 \\
240 & 2.6 & 92.4 & 5.6 \\
300 & 1.6 & 96.7 & 2.9 \\
600 & 0.7 & 98.1 & 1.5 \\
1200 & 0.4 & & \\
\hline
\end{tabular}

TABLe 2: The values of activation parameters $E_{a}, \Delta H_{a}^{*}$, and $\Delta S_{a}^{*}$ for mild steel in $1 \mathrm{M} \mathrm{HCl}$ in the absence and presence of optimum concentrations of Kalmegh (Andrographis paniculata) extract.

\begin{tabular}{|c|c|c|c|c|}
\hline $\begin{array}{l}\text { Inhibitor conc. } \\
(\mathrm{ppm})\end{array}$ & $\begin{array}{c}E_{a} \\
\left(\mathrm{~kJ} \mathrm{~mol}^{-1}\right)\end{array}$ & $\begin{array}{c}-\Delta H_{a}^{*} \\
\left(\mathrm{~kJ} \mathrm{~mol}^{-1}\right)\end{array}$ & $\Delta S_{a}^{*}\left(\mathrm{~kJ} \mathrm{~mol}^{-1}\right)$ & $\begin{array}{c}\Delta Q \\
\left(\mathrm{~kJ} \mathrm{~mol}^{-1}\right)\end{array}$ \\
\hline $1 \mathrm{M} \mathrm{HCl}$ & 29 & 22 & -137 & - \\
\hline $1200 \mathrm{ppm}$ & 65 & 62 & -36 & 79 \\
\hline
\end{tabular}

where $h$ is plank's constant, $N$ is Avogadro's number, $\Delta S^{*}$ is the entropy of activation, and $\Delta H^{*}$ is the enthalpy of activation. A plot of $\log C_{R} / T$ versus $1 / T$ gave a straight line (Figure 2(b)) with a slope of $-\Delta H^{*} / 2.303 R$ and an intercept of $\log R / N h+\Delta S^{*} / 2.303 R$, from which the values of $\Delta S^{*}$ and $\Delta H^{*}$ were calculated and listed in Table 2 . In both systems, the positive signs of enthalpies $\left(\Delta H^{*}\right)$ reflect the endothermic nature of dissolution process. The shift towards positive value of entropies $\left(\Delta S^{*}\right)$ implies that the activated complex in the rate determining step represents dissociation rather than association, meaning that disordering increases on going from reactants to the activated complex [25].

3.2. EIS Measurement. Impedance spectra for mild steel in $1 \mathrm{M} \mathrm{HCl}$ in absence and presence of different concentrations of Kalmegh (Andrographis paniculata) leaves extract are shown in the form of Nyquist plots (Figure 3). Nyquist plots consist of a "depressed" semicircle with one capacitive loop and depressed semicircle has a centre under the real axis. Such behaviour is characteristic for solid electrodes and often referred to as frequency dispersion and has been attributed to roughness and other inhomogeneities of solid surface [26, 27]. The Nyquist plots show a depressed capacitive loop in the high-frequency (HF) range and an inductive loop in the lower-frequency (LF) range. The HF capacitive loop can be attributed to the charge transfer reaction and time constant of the electric double layer and to the surface inhomogeneity of structural or interfacial origin, such as those found in adsorption processes [28]. The LF inductive loop may be attributed to the relaxation process obtained by adsorption species like $\mathrm{Cl}_{\text {ads }}^{-}$and $\mathrm{H}_{\text {ads }}^{+}$on the electrode surface $[29,30]$.

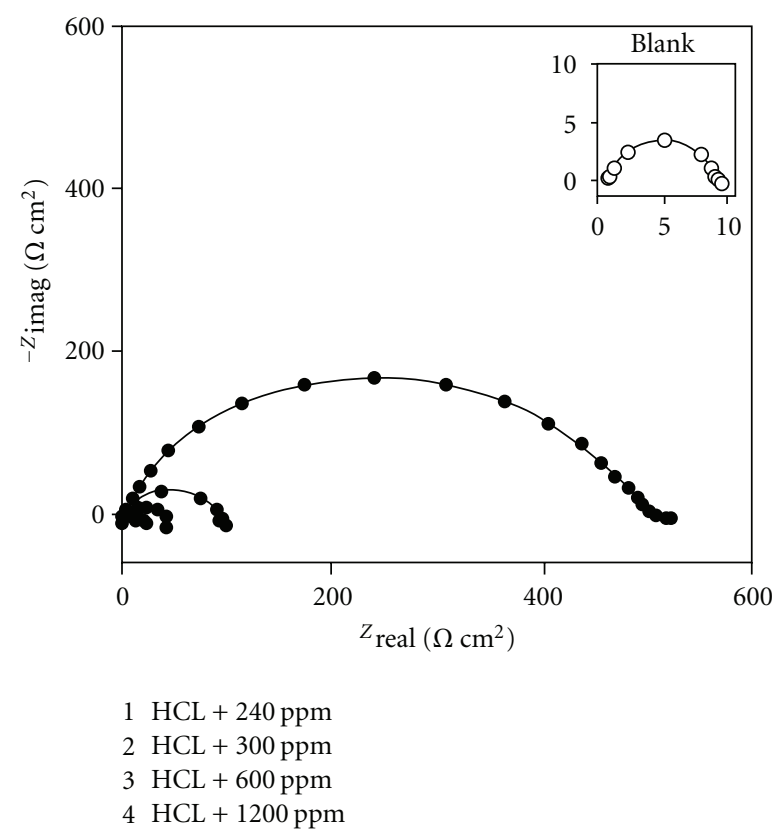

FIGURE 3: Nyquist plots in absence and presence of different concentrations of extract in $1 \mathrm{M} \mathrm{HCl}$.

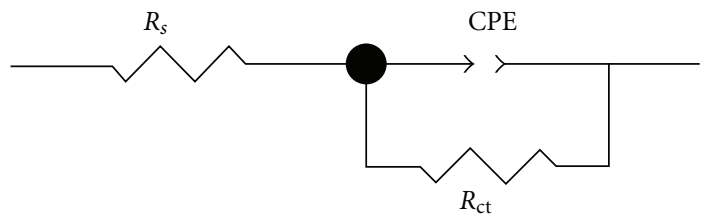

FIgURE 4: Electrochemical equivalent circuit used to fit the impedance spectra. 
TABLE 3: Electrochemical impedance parameters for mild steel in $1 \mathrm{M} \mathrm{HCl}$ in absence and presence of different concentrations of Kalmegh (Andrographis paniculata) extract.

\begin{tabular}{lccccccc}
\hline Acid Solution & Inhibitor $(\mathrm{ppm})$ & $R_{s}\left(\Omega \mathrm{cm}^{2}\right)$ & $R_{\mathrm{ct}}\left(\Omega \mathrm{cm}^{2}\right)$ & $Y_{0}\left(\Omega^{-1} \mathrm{~s}^{n} \mathrm{~cm}^{-2}\right)$ & $n$ & $C_{\mathrm{dl}}\left(\mu \mathrm{Fcm} \mathrm{cm}^{-2}\right)$ & $E(\%)$ \\
\hline $1 \mathrm{M} \mathrm{HCl}$ & 0 & 1.203 & 9 & 250 & 0.827 & 67.2 & 65.8 \\
& 180 & 1.253 & 21 & 158 & 0.864 & 58.5 \\
& 240 & 1.088 & 27 & 146 & 0.867 & 61.9 \\
& 300 & 1.137 & 99 & 105 & 0.885 & 56.9 \\
& 600 & 1.086 & 108 & 106 & 0.866 & 52.4 \\
& 1200 & 1.337 & 491 & 75 & 0.846 & 40.4 \\
\hline
\end{tabular}

The impedance spectra for Nyquist plots were analyzed by fitting to the equivalent circuit model (Figure 4) which was used elsewhere to describe iron/acid interface $[31,32]$. In this equivalent circuit, $R_{S}$ is the solution resistance, $R_{\mathrm{ct}}$ is the charge transfer resistance, and CPE is a constant phase element. The capacitance values were calculated using the following equation $[33,34]$ :

$$
Z_{\mathrm{CPE}}=Y_{0}(j \omega)^{-n},
$$

where $Y_{0}$ is the magnitude of the CPE, $j$ is the imaginary unit, $\omega$ is the angular frequency $(\omega=2 \pi f$, the frequency in $\mathrm{Hz}$ ), and $n$ is the phase shift gives details about the degree of surface inhomogeneity. When $n=1$, this is the same equation as that for the impedance of a capacitor, where $Y_{0}=$ $C_{\mathrm{dl}}$. The idealized capacitance $\left(C_{\mathrm{id}}\right)$ values were calculated from CPE parameter values $Y_{0}$ and $n$ using the following relation $[35,36]$ :

$$
C_{\mathrm{id}}=\frac{Y_{0} / \omega^{n-1}}{\sin (n(\pi / 2))} .
$$

The impedance parameters such as solution resistance $\left(R_{s}\right)$, charge transfer resistance $\left(R_{\mathrm{ct}}\right), Y_{0}, n$, derived double layer capacitance $\left(C_{\mathrm{dl}}\right)$, and inhibition efficiency $(E \%)$ are listed in Table 3. The values of $E \%$ are calculated using the following equation:

$$
E(\%)=\frac{R_{\mathrm{ct}, i}-R_{\mathrm{ct}, 0}}{R_{\mathrm{ct}, i}} \times 100,
$$

where $R_{\mathrm{ct}, i}$ and $R_{\mathrm{ct}, 0}$ are charge transfer resistances in presence and absence of inhibitor, respectively. It is clear from Table 3 that by increasing the inhibitor concentration, the $C_{\mathrm{dl}}$ values tend to decrease and the inhibition efficiency increases. The decrease in $C_{\mathrm{dl}}$ values can be attributed to a decrease in local dielectric constant and/or an increase in the thickness of the electrical double layer, suggesting that Kalmegh (Andrographis paniculata) leaves extract acts by adsorption at the mild steel/solution interface [37]. On the other hand, the values of $C_{\mathrm{dl}}$ decreased with an increase in the extract concentration. This situation was the result of an increase in the surface coverage by this inhibitor, which led to an increase in the inhibition efficiency. The values of the phase shift indicate that the $C_{\mathrm{dl}}$ values are in reasonable confidence limit. Also any significant change in the values of the phase shift, $n$, was not observed in the absence and in the presence of Kalmegh (Andrographis paniculata) leaves extract. To predict the dissolution mechanism, the value of $n$ can be used as an indicator [38]. The values of $n$, ranging between 0.827 and 0.880 , indicate that the charge transfer process controls the dissolution mechanism of mild steel in one molar $\mathrm{HCl}$ solution in the absence and in the presence of the extract. The thickness of the protective layer, $\delta_{\text {org }}$, was related to $C_{\mathrm{dl}}$ by the following equation [39]

$$
\delta_{\text {org }}=\frac{\varepsilon_{0} \varepsilon_{r}}{C_{\mathrm{dl}}}
$$

where $\varepsilon_{0}$ is the dielectric constant of the vacuum and $\varepsilon_{r}$ is the dielectric constant of the inhibitor. This decrease in the $C_{\mathrm{dl}}$, which can result from a decrease in local dielectric constant and/or an increase in the thickness of the electrical double layer, suggested that Kalmegh (Andrographis paniculata) leaves extract functions by adsorption at the metal/solution interface. Thus, the change in $C_{\mathrm{dl}}$ values was caused by the gradual replacement of water molecules by the adsorption of the organic molecules on the metal surface, decreasing the extent of metal dissolution [40].

It is apparent from Nyquist plots that the impedance response of mild steel in inhibited $\mathrm{HCl}$ solution has significantly changed after the addition of Kalmegh (Andrographis paniculata) leaves extract in acid solution and that the impedance of inhibited substrate increases with increasing concentration of inhibitor. The Nyquist plots showed that on increasing Kalmegh (Andrographis paniculata) leaves concentration, charge transfer resistance increases and double layer capacitance decreases. From the Table 3, it is clear that the greatest effect was observed at 1200 ppm of Kalmegh (Andrographis paniculata) leaves extract which gives $R_{\mathrm{ct}}$ value of $262.4 \Omega \mathrm{cm}^{2}$ in $1 \mathrm{M} \mathrm{HCl}$, respectively. Inhibition efficiency is found to increase with inhibitor concentration in the acid. The data obtained from EIS are in good agreement with those obtained from weight loss method.

3.3. Polarization Measurements. Polarization curves for mild steel at various concentration of Kalmegh (Andrographis paniculata) leaves extract in aerated solutions are shown in Figure 5. The extrapolation of Tafel straight line allows the calculation of the corrosion current density $\left(I_{\text {corr }}\right)$. The values of $I_{\text {corr }}$, the corrosion potential $\left(E_{\text {corr }}\right)$, cathodic and anodic Tafel slopes $\left(b_{c}, b_{a}\right)$, and inhibition efficiency $(E \%)$ are 
TABle 4: Potentiodynamic polarization parameters for mild steel without and with different concentrations of Kalmegh (Andrographis paniculata) extract in $1 \mathrm{M} \mathrm{HCl}$.

\begin{tabular}{|c|c|c|c|c|c|c|c|c|}
\hline \multirow{2}{*}{$\begin{array}{l}\text { Name of } \\
\text { inhibitor }\end{array}$} & \multirow{2}{*}{$\begin{array}{l}\text { Conc. Of } \\
\text { inhibitor } \\
(\mathrm{ppm})\end{array}$} & \multicolumn{5}{|c|}{ Tafel data } & \multicolumn{2}{|c|}{ Linear polarization data } \\
\hline & & $\begin{array}{c}E_{\text {corr }} \\
(\mathrm{mV} \text { versus SCE })\end{array}$ & $\begin{array}{c}I_{\text {corr }} \\
\left(\mu \mathrm{Acm}^{-2}\right)\end{array}$ & $\begin{array}{c}\beta_{a} \\
(\mathrm{mV} / \mathrm{dec})\end{array}$ & $\begin{array}{c}\beta_{c} \\
(\mathrm{mV} / \mathrm{dec})\end{array}$ & $\begin{array}{c}E \\
(\%) \\
\end{array}$ & $\begin{array}{c}R_{p} \\
\left(\Omega \mathrm{cm}^{2}\right)\end{array}$ & $\begin{array}{c}E \\
(\%) \\
\end{array}$ \\
\hline \multirow[t]{6}{*}{$1 \mathrm{M} \mathrm{HCl}$} & 0 & -446 & 1540 & 90 & 121 & - & 9.7 & - \\
\hline & 180 & -460 & 408 & 63 & 114 & 73.5 & 24.3 & 60.1 \\
\hline & 240 & -461 & 399 & 59 & 103 & 74 & 29.7 & 67.3 \\
\hline & 300 & -489 & 82 & 82 & 156 & 94.6 & 152 & 93.6 \\
\hline & 600 & -462 & 59 & 58 & 104 & 96.1 & 160.4 & 93.9 \\
\hline & 1200 & -486 & 37 & 38 & 36 & 98 & 383.5 & 97.4 \\
\hline
\end{tabular}

given in Table 4 . The $(E \%)$ is calculated using the following equation:

$$
E(\%)=\left(\frac{I_{\text {corr }}^{0}-I_{\text {corr }}^{i}}{I_{\text {corr }}^{0}}\right) \times 100 \text {, }
$$

where $I_{\text {corr }}^{0}$ and $I_{\text {corr }}^{i}$ are the corrosion current density values without and with inhibitor, respectively. Some of the authors proposed the following mechanism for the corrosion of iron and steel in acid solution [41-43]:

$$
\begin{gathered}
\mathrm{Fe}+\mathrm{Cl}^{-} \longrightarrow\left(\mathrm{FeCl}^{-}\right)_{\mathrm{ads}}, \\
\left(\mathrm{FeCl}^{-}\right)_{\mathrm{ads}} \longrightarrow(\mathrm{FeCl})_{\mathrm{ads}}+\mathrm{e}^{-}, \\
(\mathrm{FeCl})_{\mathrm{ads}} \longrightarrow\left(\mathrm{FeCl}^{+}\right)_{\mathrm{ads}}+\mathrm{e}^{-}, \\
\left(\mathrm{FeCl}^{+}\right)_{\mathrm{ads}} \longrightarrow\left(\mathrm{Fe}^{2+}\right)_{\mathrm{ads}}+\mathrm{Cl}^{-} .
\end{gathered}
$$

The cathodic hydrogen evolution

$$
\begin{gathered}
\mathrm{Fe}+\mathrm{H}^{+} \longrightarrow\left(\mathrm{FeH}^{+}\right)_{\mathrm{ads}}, \\
\left(\mathrm{FeH}^{+}\right)_{\mathrm{ads}}+\mathrm{e}^{-} \longrightarrow(\mathrm{FeH})_{\mathrm{ads}}, \\
\left(\mathrm{FeH}^{+}\right)_{\mathrm{ads}}+\mathrm{H}^{+}+\mathrm{e}^{-} \longrightarrow \mathrm{Fe}+\mathrm{H}_{2}
\end{gathered}
$$

The change in $b_{a}$ and $b_{c}$ values as shown in Table 4 indicates that adsorption of Kalmegh (Andrographis paniculata) leaves extract modifies the mechanism of anodic dissolution as well as cathodic hydrogen evolution. From the Figure 5, it is clear that both the cathodic and anodic reactions are inhibited and the inhibition increases as the inhibitor conc. increases in acid media, but the cathode is more polarized. From the Table 4, it is clear that there was no definite trend in the shift of $E_{\text {corr }}$ values, in the presence of various concentration of Kalmegh (Andrographis paniculata) leaves extract in $1 \mathrm{M} \mathrm{HCl}$ solution. This result indicated that Kalmegh (Andrographis paniculata) leaves extract can be classified as mixed type of inhibitor in $1 \mathrm{M} \mathrm{HCl}$ solution.

3.4. Adsorption Isotherm. Basic information on the interaction between the inhibitor and the mild steel surface can be provided by the adsorption isotherm. For this purpose, the values of surface coverage $(\theta)$ at different concentrations

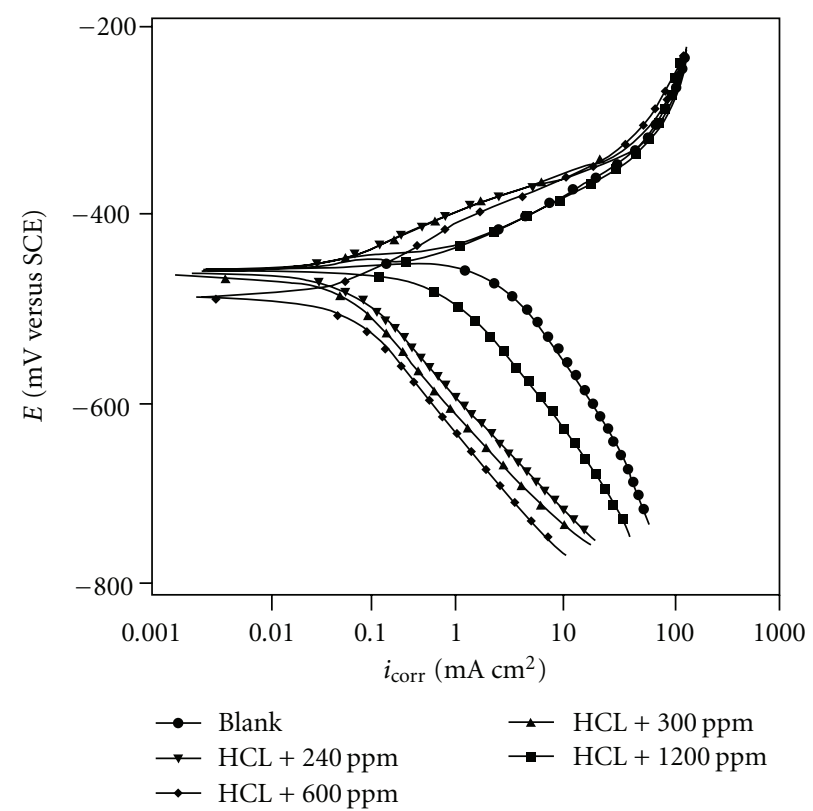

Figure 5: Polarization curves in absence and presence of different concentrations of extract in $1 \mathrm{M} \mathrm{HCl}$.

of Kalmegh (Andrographis paniculata ) leaves extract in acid media in the temperature range $(308-\overline{3} 38 \mathrm{~K})$ have been used to explain the best isotherm to determine the adsorption process. The adsorption of an organic adsorbate on to metal-solution interface was donated by a substitutional adsorption process between the organic molecules in the aqueous solution $\mathrm{Org}_{(\text {sol })}$ and the water molecules on the metallic surface $\mathrm{H}_{2} \mathrm{O}_{(\text {sol })}$ [44],

$$
\mathrm{Org}_{(\mathrm{sol})}+x \mathrm{H}_{2} \mathrm{O} \longrightarrow \mathrm{Org}_{(\mathrm{ads})}+x \mathrm{H}_{2} \mathrm{O}_{(\mathrm{sol})}
$$

where $\mathrm{Org}_{(\text {(sol) }}$ and $\mathrm{Org}_{(\text {ads })}$ are the organic molecules in the aqueous solutions and adsorbed on the metallic surface, respectively, $\mathrm{H}_{2} \mathrm{O}_{(\text {ads })}$ is the water molecules on the metallic surface, and $x$ is the size ratio representing the number of water molecules replaced by one molecule of organic adsorbate.

Attempts were made to fit these $\theta$ values to various isotherm including Frumkin, Langmuir, and Temkin. According to 
TABle 5: Prominent peaks obtained from reflectance FTIR spectroscopy.

\begin{tabular}{lc}
\hline Frequency $\left(\mathrm{cm}^{-1}\right)$ & Band assignment \\
\hline 1080 & $\mathrm{C}-\mathrm{O}$ stretching \\
1226 & $\mathrm{C}-\mathrm{O}$ stretching \\
1373 & $\mathrm{C}-\mathrm{H}$ bending (methyl) \\
1725 & $\mathrm{C}=\mathrm{O}$ stretching \\
2880 & $\mathrm{C}-\mathrm{H}$ stretching \\
3268 & $\mathrm{O}-\mathrm{H}$ stretching \\
\hline
\end{tabular}

these isotherms, $\theta$ is related to the inhibitor concentration $\left(C_{\text {inh }}\right)$ as follow:

$$
\begin{gathered}
\theta=\frac{b C_{\text {inh }}}{1+b C_{\text {inh }}} \quad(\text { Langmuir isotherm), } \\
\exp (-2 a \theta)=K C_{\text {inh }} \quad \text { (Temkin isotherm), }
\end{gathered}
$$

where $b$ designates the adsorption coefficient in (16), $a$ is the molecular interaction parameter, and $K$ is the equilibrium constant of the adsorption process in (17). The best fit was obtained with Langmuir isotherm as in Figure 6. The value of $b$ indicates that Kalmegh (Andrographis paniculata) leaves extract is strongly adsorbed on the steel surface. This is in good agreement with the results obtained from impedance spectroscopy and polarization measurements. The first stage in the action mechanism of inhibitor in acid media is adsorption on the metal surface [45]. In most inhibition studies, the formation of donor-acceptor surface complexes between $\pi$-electrons of inhibitor and the vacant d-orbital of metal was postulated [46].

3.5. Fourier Transform Infrared Spectroscopy (FTIR) Analysis. It is well established that FTIR spectrophotometer is a powerful tool that can be used to identify the type of bonding particularly functional group(s) present in organic compounds. Since extracts contained organic compounds and these organic compounds were adsorbed on the metal surface providing protection against corrosion. So, FTIR analyses of metal surface can be useful for predicting whether organic inhibitors are adsorbed or not adsorbed on the metal surface. In present study, reflectance FTIR spectra were used to support the fact that corrosion inhibition of mild steel in acid media is due to the adsorption of inhibitor molecules on the mild steel surface. The prominent peaks are given in Table 5. From data in Table 5, we conclude that reflectance FTIR spectra support good inhibition performance of Kalmegh (Andrographis paniculata) leaves extract for mild steel corrosion in molar hydrochloric acid solution.

\section{Mechanism of Inhibition}

The main constituent of Kalmegh (Andrographis paniculata) leaves extract is Andrographolide whose structures are given in Figure 7, having multiple bonds through which they get adsorbed on the mild steel surface. The high performance

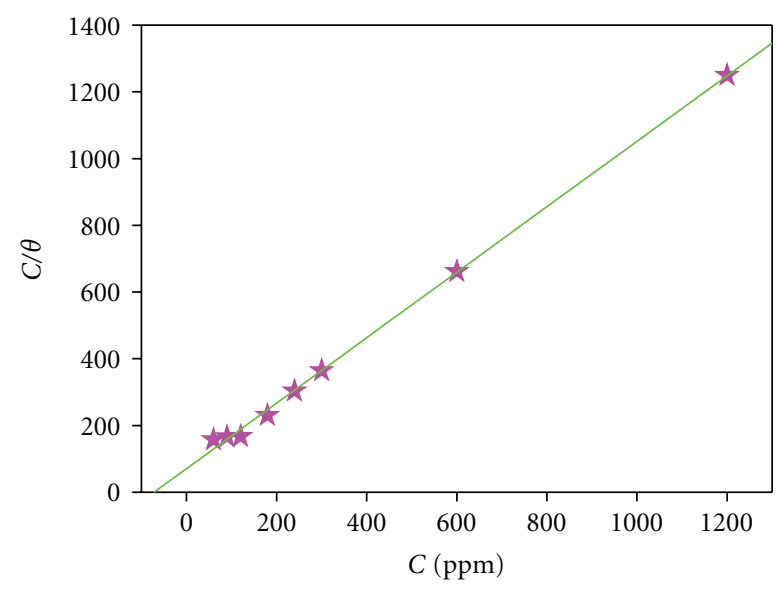

FIGURE 6: Langmuir adsorption isotherm plot for the adsorption of extract in $1 \mathrm{M} \mathrm{HCl}$ on the surface of mild steel.

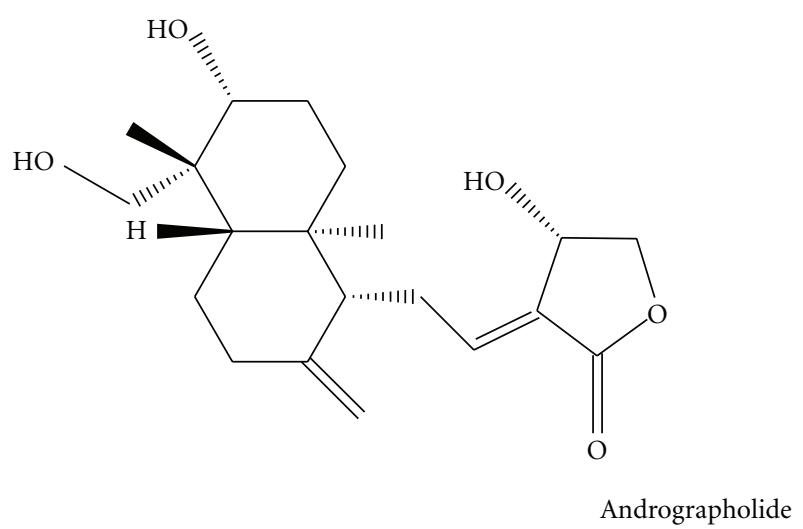

FIGURE 7: Structure of main constituents of Kalmegh (Andrographis paniculata) extracts (a) Andrographolide.

of Kalmegh (Andrographis paniculata) leaves extract could also be due to large size of constituent's molecule which covers wide areas on the metal surface and thus retarding the corrosion [47]. Kalmegh (Andrographis paniculata) leaves extract is composed of numerous naturally occurring organic compounds. The inhibitive action of Kalmegh (Andrographis paniculata) leaves extract toward the acid corrosion of steel can be attributed to the adsorption of Kalmegh (Andrographis paniculata) leaves extract components onto the steel surface. FTIR showed that the leaves extract contains oxygen atoms in functional groups $(\mathrm{O}-\mathrm{H}, \mathrm{C}=\mathrm{C}, \mathrm{C}=\mathrm{O}, \mathrm{C}-$ $\mathrm{H}, \mathrm{C}-\mathrm{O})$ and aromatic ring, which meets the general consideration of typical corrosion inhibitors. The nonbonded electrons of heteroatoms get protonated and thereby they get adsorbed on the negatively charged metal surface. Due to electrostatic interaction, the protonated constituent's molecules are adsorbed (physisorption) and high inhibition is expected. Kalmegh (Andrographis paniculata) leaves extract molecules can also adsorb on the metal surface on the basis of donor-acceptor interactions between $\pi$-electrons of aromatic ring and vacant d-orbitals of Fe. When protonated Kalmegh (Andrographis paniculata) leaves extract adsorbed 
on metal surface, coordinate bond may be formed by partial transference of electrons from the polar atoms ( $\mathrm{O}$ atoms) to the metal surface.

This assumption could be further confirmed by the FTIR results that Kalmegh (Andrographis paniculata) leaves extract could adsorb onto steel surface to form a dense and more tightly protective film covering both cathodic and anodic reaction sites and, thus, retarding corrosion phenomenon.

\section{Conclusions}

(1) The adsorption of Kalmegh (Andrographis paniculata) leaves extract obeyed Langmuir adsorption isotherm.

(2) Kalmegh (Andrographis paniculata) leaves extract acted as mixed type inhibitor.

(3) The increasing value of CPE exponent, that is, phase shift $(n)$ with increasing inhibitor concentration indicated that surface roughness decreased with increasing inhibitor concentration.

(4) The FTIR spectrum showed that the inhibition is due to the formation of the film on the metal/acid solution interface through adsorption of Kalmegh (Andrographis paniculata) leaves extract molecules.

\section{References}

[1] H. Ashassi-Sorkhabi, D. Seifzadeh, and M. G. Hosseini, "EN, EIS and polarization studies to evaluate the inhibition effect of 3H-phenothiazin-3-one, 7-dimethylamin on mild steel corrosion in $1 \mathrm{M} \mathrm{HCl}$ solution," Corrosion Science, vol. 50, no. 12, pp. 3363-3370, 2008.

[2] A. K. Satapathy, G. Gunasekaran, S. C. Sahoo, K. Amit, and P. V. Rodrigues, "Corrosion inhibition by Justicia gendarussa plant extract in hydrochloric acid solution," Corrosion Science, vol. 51, p. 2848, 2009.

[3] A. M. Abdel-Gaber, E. Khamis, H. Abo-ElDahab, and S. Adeel, "Inhibition of aluminium corrosion in alkaline solutions using natural compound," Materials Chemistry and Physics, vol. 109, no. 2-3, pp. 297-305, 2008.

[4] A. M. Abdel-Gaber, B. A. Abd-El-Nabey, and M. Saadawy, "The role of acid anion on the inhibition of the acidic corrosion of steel by lupine extract," Corrosion Science, vol. 51, no. 5, pp. 1038-1042, 2009.

[5] P. B. Raja and M. G. Sethuraman, "Natural products as corrosion inhibitor for metals in corrosive media-a review," Materials Letters, vol. 62, no. 1, pp. 113-116, 2008.

[6] E. A. Noor, "Comparative study on the corrosion inhibition of mild steel by aqueous extract of Fenugreek seeds and leaves in acidic solution," Journal of Engineering and Applied Sciences, vol. 3, no. 1, pp. 23-30, 2008.

[7] J. Buchweishaija and G. S. Mhinzi, "Natural products as a source of environmentally friendly corrosion inhibitors: the case of gum exudate from Acacia seyal var. seyal," Portugaliae Electrochimica Acta, vol. 26, no. 3, pp. 257-265, 2008.

[8] E. E. Oguzie, "Evaluation of the inhibitive effect of some plant extracts on the acid corrosion of mild steel," Corrosion Science, vol. 50, no. 11, pp. 2993-2998, 2008.
[9] P. C. Okafor, M. E. Ikpi, I. E. Uwah, E. E. Ebenso, U. J. Ekpe, and S. A. Umoren, "Inhibitory action of Phyllanthus amarus extracts on the corrosion of mild steel in acidic media," Corrosion Science, vol. 50, no. 8, pp. 2310-2317, 2008.

[10] M. A. Quraishi, A. Singh, V. K. Singh, D. K. Yadav, and A. K. Singh, "Green approach to corrosion inhibition of mild steel in hydrochloric acid and sulphuric acid solutions by the extract of Murraya koenigii leaves," Materials Chemistry and Physics, vol. 122, no. 1, pp. 114-122, 2010.

[11] E. A. Noor, "Potential of aqueous extract of Hibiscus sabdariffa leaves for inhibiting the corrosion of aluminum in alkaline solutions," Journal of Applied Electrochemistry, vol. 39, no. 9, pp. 1465-1475, 2009.

[12] F. S. de Souza and A. Spinelli, "Caffeic acid as a green corrosion inhibitor for mild steel," Corrosion Science, vol. 51, no. 3, pp. 642-649, 2009.

[13] A. M. Badiea and K. N. Mohana, "Corrosion mechanism of low-carbon steel in industrial water and adsorption thermodynamics in the presence of some plant extracts," Journal of Materials Engineering and Performance, vol. 18, no. 9, pp. 1264-1271, 2009.

[14] L. R. Chauhan and G. Gunasekaran, "Corrosion inhibition of mild steel by plant extract in dilute $\mathrm{HCl}$ medium," Corrosion Science, vol. 49, no. 3, pp. 1143-1161, 2007.

[15] A. Y. El-Etre, M. Abdallah, and Z. E. El-Tantawy, "Corrosion inhibition of some metals using lawsonia extract," Corrosion Science, vol. 47, no. 2, pp. 385-395, 2005.

[16] K. O. Orubite and N. C. Oforka, "Inhibition of the corrosion of mild steel in hydrochloric acid solutions by the extracts of leaves of Nypa fruticans Wurmb," Materials Letters, vol. 58, no. 11, pp. 1768-1772, 2004.

[17] A. Ninčević Grassino, Z. Grabarić, A. Pezzani, G. Fasanaro, and A. L. Voi, "Influence of essential onion oil on tin and chromium dissolution from tinplate," Food and Chemical Toxicology, vol. 47, no. 7, pp. 1556-1561, 2009.

[18] A. A. Torres-Acosta, "Opuntia-Ficus-Indica (Nopal) mucilage as a steel corrosion inhibitor in alkaline media," Journal of Applied Electrochemistry, vol. 37, no. 7, pp. 835-841, 2007.

[19] M. Schorr and J. Yahalom, "The significance of the energy of activation for the dissolution reaction of metal in acids," Corrosion Science, vol. 12, no. 11, pp. 867-868, 1972.

[20] M. A. Quraishi and S. Khan, “Thiadiazoles-A potential class of heterocyclic inhibitors for prevention of mild steel corrosion in hydrochloric acid solution," Indian Journal of Chemical Technology, vol. 12, no. 5, pp. 576-581, 2005.

[21] C. B. Breslin and W. M. Carroll, "The activation of aluminium by indium ions in chloride, bromide and iodide solutions," Corrosion Science, vol. 34, no. 2, pp. 327-341, 1993.

[22] M. G. A. Khedr and A. M. S. Lashien, "The role of metal cations in the corrosion and corrosion inhibition of aluminium in aqueous solutions," Corrosion Science, vol. 33, no. 1, pp. 137-151, 1992.

[23] I. N. Putilova, S. A. Balezin, and U. P. Barannik, Metallic Corrosion Inhibitor, Pergamon Press, New York, NY, USA, 1960.

[24] J. O. M. Bockris and A. K. N. Reddy, Modern Electrochemistry, Plenum Press, New York, NY, USA, 1977.

[25] R. A. Prabhu, A. V. Shanbhag, and T. V. Venkatesha, "Influence of tramadol [2-[(dimethylamino)methyl]-1-(3methoxyphenyl) cyclohexanol hydrate] on corrosion inhibition of mild steel in acidic media," Journal of Applied Electrochemistry, vol. 37, no. 4, pp. 491-497, 2007. 
[26] M. Elayyachy, A. El Idrissi, and B. Hammouti, "New thiocompounds as corrosion inhibitor for steel in $1 \mathrm{M} \mathrm{HCl}$," Corrosion Science, vol. 48, no. 9, pp. 2470-2479, 2006.

[27] S. Martinez and M. Metikoš-Huković, "A nonlinear kinetic model introduced for the corrosion inhibitive properties of some organic inhibitors," Journal of Applied Electrochemistry, vol. 33, no. 12, pp. 1137-1142, 2003.

[28] I. Ahamad and M. A. Quraishi, "Mebendazole: new and efficient corrosion inhibitor for mild steel in acid medium," Corrosion Science, vol. 52, no. 2, pp. 651-656, 2010.

[29] A. Yurt, G. Bereket, A. Kivrak, A. Balaban, and B. Erk, "Effect of Schiff bases containing pyridyl group as corrosion inhibitors for low carbon steel in 0.1 M HCl," Journal of Applied Electrochemistry, vol. 35, no. 10, pp. 1025-1032, 2005.

[30] M. A. Amin, S. S. Abd El-Rehim, E. E. F. El-Sherbini, and R. S. Bayoumi, "The inhibition of low carbon steel corrosion in hydrochloric acid solutions by succinic acid: Part I. Weight loss, polarization, EIS, PZC, EDX and SEM studies," Electrochimica Acta, vol. 52, no. 11, pp. 3588-3600, 2007.

[31] F. Mansfeld, "Recording and analysis of AC impedance data for corrosion studies," Corrosion Science, vol. 36, no. 5, pp. 301307,1981 .

[32] M. Hosseini, S. F. L. Mertens, M. Ghorbani, and M. R. Arshadi, "Asymmetrical Schiff bases as inhibitors of mild steel corrosion in sulphuric acid media," Materials Chemistry and Physics, vol. 78, no. 3, pp. 800-808, 2003.

[33] J. Shukla and K. S. Pitre, "Electrochemical behavior of brass in acid solutions and the inhibitive effect of imidazole," Corrosion Reviews, vol. 20, no. 3, pp. 217-229, 2002.

[34] M. Mahdavian and M. M. Attar, "Electrochemical behaviour of some transition metal acetylacetonate complexes as corrosion inhibitors for mild steel," Corrosion Science, vol. 51, no. 2, pp. 409-414, 2009.

[35] S. F. L. Mertens, Ph.D. dissertation, Ghent University, Ghent, Belgium, 1999.

[36] I. Ahamad and M. A. Quraishi, "Mebendazole: new and efficient corrosion inhibitor for mild steel in acid medium," Corrosion Science, vol. 52, no. 2, pp. 651-656, 2010.

[37] A. Yurt, G. Bereket, A. Kivrak, A. Balaban, and B. Erk, "Effect of Schiff bases containing pyridyl group as corrosion inhibitors for low carbon steel in 0.1 M HCl," Journal of Applied Electrochemistry, vol. 35, no. 10, pp. 1025-1032, 2005.

[38] M. A. Quraishi and R. Sardar, "Hector bases-a new class of heterocyclic corrosion inhibitors for mild steel in acid solutions," Journal of Applied Electrochemistry, vol. 33, no. 12, pp. 1163-1168, 2003.

[39] F. Bentiss, M. Lagrenée, B. Elmehdi, B. Mernari, M. Traisnel, and $\mathrm{H}$. Vezin, "Electrochemical and quantum chemical studies of 3,5-di (n-tolyl)-4-amino-1,2,4-triazole adsorption on mild steel in acidic media," Corrosion, vol. 58, no. 5, pp. 399-407, 2002.

[40] R. R. Anand, R. M. Hurd, and N. Hackerman, "Adsorption of monomeric and polymeric amino corrosion inhibitors on steel," Journal of the Electrochemical Society, vol. 112, no. 2, pp. 138-144, 1965.

[41] M. S. Morad and A. M. K. El-Dean, "2,2' -dithiobis(3-cyano4,6-dimethylpyridine): a new class of acid corrosion inhibitors for mild steel," Corrosion Science, vol. 48, no. 11, pp. 3398 $3412,2006$.

[42] K. Tebbji, B. Hammouti, H. Oudda, A. Ramdani, and M. Benkadour, "The inhibitive effect of bipyrazolic derivatives on the corrosion of steel in hydrochloric acid solution," Applied Surface Science, vol. 252, no. 5, pp. 1378-1385, 2005.
[43] A. Yurt, A. Balaban, S. U. Kandemir, G. Bereket, and B. Erk, "Investigation on some Schiff bases as $\mathrm{HCl}$ corrosion inhibitors for carbon steel," Materials Chemistry and Physics, vol. 85, no. 2-3, pp. 420-426, 2004.

[44] G. K. Gomma and M. H. Wahdan, "Effect of temperature on the acidic dissolution of copper in the presence of amino acids," Materials Chemistry and Physics, vol. 39, no. 2, pp. 142148, 1994.

[45] M. A. Quraishi and R. Sardar, "Hector bases—a new class of heterocyclic corrosion inhibitors for mild steel in acid solutions," Journal of Applied Electrochemistry, vol. 33, no. 12, pp. 1163-1168, 2003.

[46] S. Muralidharan, M. A. Quraishi, and S. V. K. Iyer, "The effect of molecular structure on hydrogen permeation and the corrosion inhibition of mild steel in acidic solutions," Corrosion Science, vol. 37, no. 11, pp. 1739-1750, 1995.

[47] G. Trabenelli and F. Mansfeld, Corrosion Mechanisms, Marcel Dekker, New York, NY, USA, 1987. 

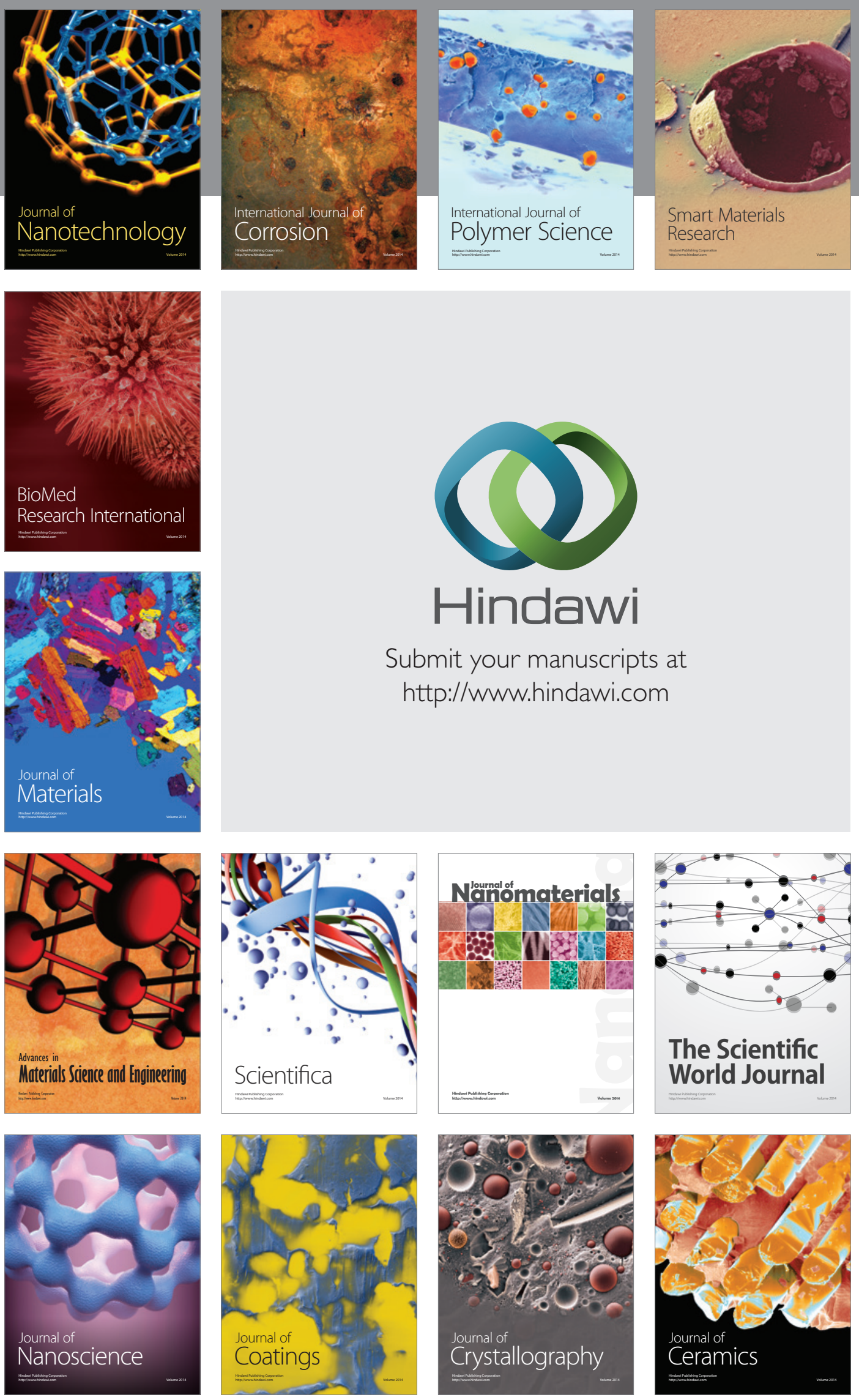

The Scientific World Journal

Submit your manuscripts at

http://www.hindawi.com

\section{World Journal}

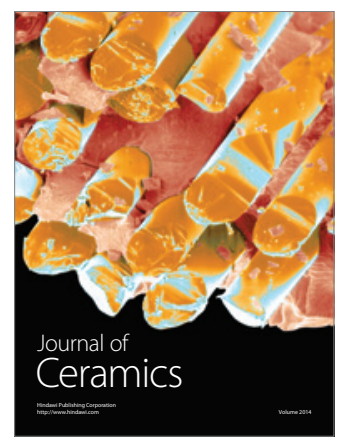

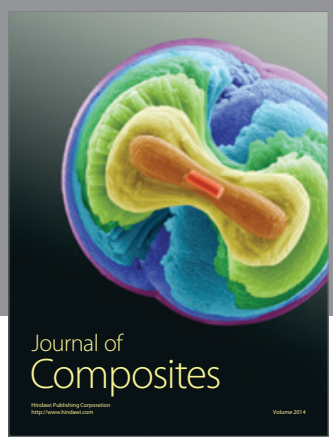
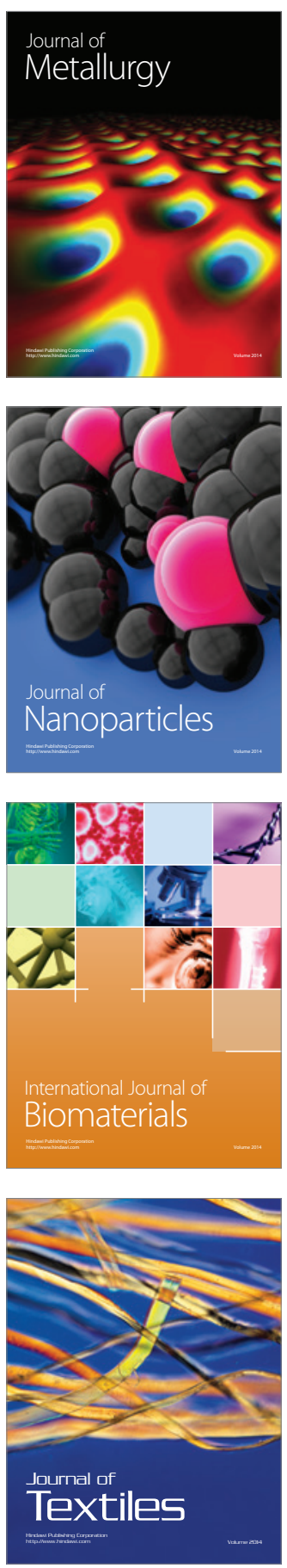